\title{
Parathyroid Carcinoma in a Center Routinely Using ioPTH: A Case Series
}

\author{
Mechteld C de Jong ${ }^{1}$, Michael Shawky ${ }^{2}$, Virginia Rozalén García ${ }^{3}$, Tom R Kurzawinski ${ }^{4}$, Tarek E Abdel-Aziz ${ }^{5}$
}

\begin{abstract}
Aim: Parathyroid carcinoma (PC) is a rare endocrine malignancy and therefore limited data are currently available. In this case series, we describe our institution's experience with PC and patients' outcomes.

Background: The course of PC ranges from indolent to progressive disease with an uncontrollable hypercalcemia and widespread metastases. No clear guidelines toward diagnosis as well as management currently exist owing to a lack of prospective data.

Case description: Here, we present a case series of 12 patients who underwent treatment for PC at our institution. All patients were diagnosed after surgery. At time of surgery, three patients (25.0\%) underwent a concomitant hemithyroidectomy owing to abnormal features. An additional four patients (33.3\%) underwent a hemithyroidectomy on the side of their PC. None of our patients received any adjuvant medical therapy. One patient ( $8.3 \%)$ was found to have recurrent disease; this patient is currently alive with disease.

Conclusion: In conclusion, although no uniform management strategy was observed during the included period, overall outcomes were good, with a recurrence rate of less than $10 \%$.

Clinical significance: PC is a very uncommon malignancy that imposes both diagnostic and management uncertainties. The current report describes the management and outcomes of a series of 12 patients with this disease. All patients were only diagnosed after surgery as having a PC. Moreover, possibly due to a lack of prospective data, all patients in our series underwent different surgical treatment strategies. Nonetheless, overall, both short- and long-term outcomes were satisfactory, with a less than $10 \%$ recurrence rate. However, this series does underline the importance of more prospective research regarding diagnostic, treatment, and prognostic variables for PC.

Keywords: Management, Outcomes, Parathyroid carcinoma, PTH.

World Journal of Endocrine Surgery (2019): 10.5005/jp-journals-10002-1261
\end{abstract}

\section{BACKGROUND}

Parathyroid carcinoma (PC), first described in $1933,{ }^{1}$ is extremely rare and possibly the most uncommon endocrine malignancy. ${ }^{2}$ The diagnosis of PC proves challenging, as there is a lack of distinct clinical and histopathological features. ${ }^{3}$ While the natural course of PC could be indolent, progressive disease with uncontrollable hypercalcemia and widespread metastatic disease have been described. ${ }^{4}$

In this case series, we describe our institution's experience with PC and patients' outcomes. Also, at our institution, intraoperative PTH (ioPTH) measurements as a point-of-care test for intraoperative cure of hyperparathyroidism-using the modified Miami criterion-is routinely employed. ${ }^{5}$ As PCs are known to be more hormonally active than benign parathyroid adenomas, ${ }^{4}$ we aimed to explore whether this possibly increased hormonal activity can be seen in these patients' ioPTH-results.

\section{Case Description}

Between 1 January 2005 and 31 December 2016, 587 patients underwent a parathyroidectomy for single gland, primary hyperparathyroidism at our institution. All data on these patients were collected in an institutional database. Of these patients, 12 patients $(2.0 \%)$ were found to have PC on a histopathological examination.

All 12 patients had symptoms related to hypercalcemia, of which malaise was most common $(n=12 ; 100 \%)$. In five patients $(41.7 \%)$, the malaise was so severe, and it required a visit to $A$ and $E$. One-third of patients ( $n=4 ; 33.3 \%$ ) had signs of bone disease, while one of these patients $(n=1 ; 8.3 \%)$ also suffered from kidney
${ }^{1-4}$ Center for Endocrine Surgery, University College London Hospital, London, United Kingdom

${ }^{5}$ Center for Endocrine Surgery, University College London Hospital, London, United Kingdom; Department of General Surgery, Alexandria University, Alexandria, Egypt

Corresponding Author: Mechteld $\mathrm{C}$ de Jong, Center for Endocrine Surgery, University College London Hospital, London, United Kingdom, Phone: +44 2034567890, e-mail: mechteld.dejong@nhs.net

How to cite this article: de Jong MC, Shawky M, et al. Parathyroid Carcinoma in a Center Routinely Using ioPTH: A Case Series. World J Endoc Surg 2019;11(2):57-59.

Source of support: Nil

Conflict of interest: None

stones. None of our patients presented with a visible neck mass. More details on our patients are described in Table 1 (left column).

All patients underwent an ultrasound scan and a ${ }^{99 m} \mathrm{Tc}$ Sestamibi scan (both $n=12 ; 100 \%$ ); importantly, none of the patients showed any alarming features on their ultrasound scan. Moreover, none displayed a lymph node metastasis on imaging of the cervical lymph nodes at the time of presentation. The median size of the gland was $2.10 \mathrm{~cm}$ (range: 0.2-4.4) on imaging.

At the time of surgery, unusual findings were noted in the operation report of half of our included patients $(n=6 ; 50.0 \%)$. In three of these patients (25.0\%), the parathyroid gland was described as being "very large", "being intra-thyroidal and difficult to dissect," and as a "hard mass not infiltrating the thyroid", respectively. All of these patients underwent only resection of the parathyroid gland. 
Table 1: Differences in baseline characteristics and ioPTH outcomes for patients with a parathyroid carcinoma, compared with patients with a benign parathyroid adenoma

\begin{tabular}{lllc}
\hline & \multicolumn{2}{c}{ Number $(n=587)(\%)$} \\
\cline { 2 - 3 } Variable & \multicolumn{3}{c}{ Parathyroid adenoma } \\
$(n=575)$ & 0.09 \\
\hline Sex (female) & $6(50.0)$ & $427(74.3)$ & 0.21 \\
Age (median [range]) & $49[18-74]$ & $59[18-90]$ & 0.12 \\
Highest calcium (median [range]), $\mathrm{mmol} / \mathrm{L}$ & $2.97[2.52-3.60]$ & $3.0[2.18-3.98]$ & $<0.001$ \\
Highest PTH (median [range]), pmol/L & $93.0[6.50-458.0]$ & $13.0[3.9-92.1]$ & 0.08 \\
Size on imaging (median [range]), $\mathrm{cm}$ & $2.10[0.2-4.4]$ & $1.0[0.1-4.4]$ & \\
ioPTH & & & $<0.001$ \\
$\quad$ Highest value (median [range]), pmol/L & $55.15[26.7-272.3]$ & $24.3[2.6-405.0]$ & $<0.001$ \\
$\quad$ Drop in level (median [range]), pmol/L & $49.5[23.4-232.5]$ & $19.5[0.8-376.1]$ & 0.009 \\
$\quad$ Drop in ioPTH-level, \% & $88.7[64.2-92.2]$ & $81.4[18.5-97.5]$ & \\
\hline
\end{tabular}

Conversely, in an additional three patients (25.0\%), where the parathyroid gland was described as having "infiltrative features", being "extremely difficult to dissect," and being "very large", respectively, it resulted in a concomitant hemithyroidectomy.

Overall, the median highest ioPTH level was $55.15 \mathrm{pmol} / \mathrm{L}$ (range: 26.7-272.3). Upon further exploring the outcomes of the ioPTH measurement among our study series, the levels for the 12 patients who had PC were compared to patients who underwent surgery for primary hyperparathyroidism owing to a benign parathyroid adenoma (PA) $(n=575)$ during the same period. The results of this comparison are shown in Table 1.

The median length of stay for our 12 patients was 1 day (range: $1-19)$, which is probably skewed to the right because one patient (8.3\%) developed norovirus postoperatively and was therefore admitted for a total of 19 days. Two patients (16.7\%) developed a postoperative, symptomatic hypocalcemia, requiring a prolonged hospital stay and intravenous admission of calcium. Both of these patients were discharged on postoperative day three, on oral calcium-supplements. The overall median direct postoperative calcium was $2.5 \mathrm{mmol} / \mathrm{L}$ (range: 1.7-3.2) and the overall median PTH was $1.3 \mathrm{pmol} / \mathrm{L}$ (range: $0.7-14.0$ ). Moreover, none of the included patients complained of hoarseness or other symptoms, indicating damage to the recurrent laryngeal nerve.

Following their final diagnosis on histopathology, an additional four patients (33.3\%) underwent a hemithyroidectomy on the side of their PC, bringing the total number of patients in whom an ipsilateral hemithyroidectomy in addition to removal of the PC was performed to seven (58.3\%). None of our patients received any adjuvant medical therapy.

After a median follow-up of 48 months (range: 1-120), one patient $(8.3 \%)$ was found to have a recurrent disease. This patient developed pulmonary metastasis, 27 months after his initial surgery, for which he underwent a resection as well as multiple sessions of radio-ablative therapy and chemotherapy. He is currently alive with disease.

\section{Discussion}

We report on a series of 12 patients with PC of whom half were female $(n=6)$. The female-to-male ratio of $1: 1$ is similar to that reported in literature. ${ }^{4,6}$ Interestingly, the ratio female-to-male among benign disease is reported to be around $3-4: 1 .^{7}$ The median age in our series was 49 years among patients with PC. In a previous series, the average age at presentation was described to be approximately a decade younger than for patients with a benign disease, concordant with our series. 6,8

Some authors report that en-bloc resection of the affected parathyroid gland with the surrounding thyroid lobe results in improved local control and is possibly also associated with better long-term outcomes. ${ }^{2,9-11}$ However, the gold standard surgical approach for patients with PC has not been established, as-due to its rarity - there are no prospective data regarding the best initial surgical approach nor the indications for the performance of a second stage surgery. ${ }^{12}$ This can also been seen in the heterogenous management strategies observed among our 12 patients.

In literature, reports of disease recurrence are very common in PC (rates: $25-100 \%)$, sometimes occurring as late as 20 years after initial diagnosis. ${ }^{4}$ In our series, recurrence rate was less than $10 \%$; however, the median follow-up was relatively short.

The pathogenesis of PC is incompletely understood. Similar to other neuroendocrine tumors, PC generally tends to produce symptoms through hormonal secretion rather than by invasion. ${ }^{13}$ Hypercalcemia-levels of $>3.5 \mathrm{mmol} / \mathrm{L}$ have been described in previous reports. ${ }^{4,7,14}$ Moreover, reports of profoundly elevated (three to ten times of normal) PTH levels are in concordance with the median highest PTH-level of $93.0 \mathrm{pmol} / \mathrm{L}$ among our patients. ${ }^{14-18}$

Solorzano et al. ${ }^{19}$ described the use of ioPTH-monitoring among eight patients with PC. While their data showed that the ioPTH did drop for these patients, no further inferences were made in their study. Adam et al. ${ }^{6}$ also demonstrated a significantly higher baseline ioPTH in their four patients with PC compared with patients with PA. In looking at our data, both the median pre-operative PTH-levels and the median highest ioPTH measured among patients with PC was more than twice as high compared with patients with PA, but levels are overlapping significantly.

One pitfall of relying on the hormonal characteristics of PC could be that between 10 and $25 \%$ of all PCs are thought to be non-functioning. ${ }^{20,21}$ In that case, the diagnosis is based almost entirely on histological findings. ${ }^{22}$

\section{Conclusion}

$P C$ is a rare disease that is difficult to diagnose. We here report on the surgical treatment and outcomes of 12 patients who were treated for this disease. While the management among our patients was very heterogeneous, the overall outcomes were good, with a recurrence rate of less than $10 \%$. Although both pre-operative PTH and ioPTH might show signs of increased hormonal activity 
compared to PA, there is not enough evidence to support a claim for a place of ioPTH as an adjunct in the diagnosis of PC.

\section{Clinical Significance}

Parathyroid carcinoma is a very uncommon malignancy that imposes diagnostic as well as management uncertainties. The current report describes the management and outcomes of a series of twelve patients with this disease. Although our patients did not undergo a uniform surgical strategy, both short- and long-term outcomes in our series were satisfactory, with a less than $10 \%$ recurrence rate. However, this series underlines the importance of more prospective research regarding diagnostic, treatment, and prognostic variables.

\section{References}

1. Sainton P, Millot J. Malegne dun adenoma parathyroidiene eosinophile; au cours de Recklinghausen. Ann Anat Pathol 1933;10:813.

2. Sharretts JM, Kebebew E, et al. Parathyroid cancer. Semin Oncol 2010;37(6):580-590. DOI: 10.1053/j.seminoncol.2010.10.013.

3. Schulte KM, Talat N. Diagnosis and management of parathyroid cancer. Nat Rev Endocrinol 2012;8(10):612-622. DOI: 10.1038/ nrendo.2012.102.

4. McClenaghan F, Qureshi YA. Parathyroid cancer. Gland Surg 2015;4(4):329-338.

5. Barczynski M, Konturek A, et al. Evaluation of Halle, Miami, Rome, and Vienna intraoperative iPTH assay criteria in guiding minimally invasive parathyroidectomy. Langenbecks Arch Surg 2009;394(5):843-849. DOI: 10.1007/s00423-009-0510-z.

6. Adam MA, Untch BR, et al. Parathyroid carcinoma: current understanding and new insights into gene expression and intraoperative parathyroid hormone kinetics. Oncologist 2010;15(1):61-72. DOI: 10.1634/theoncologist.2009-0185.

7. Shane E. Clinical review 122: Parathyroid carcinoma. J Clin Endocrinol Metab 2001;86(2):485-493. DOI: 10.1210/jcem.86.2.7207.

8. Obara T, Fujimoto Y. Diagnosis and treatment of patients with parathyroid carcinoma: an update and review. World J Surg 1991;15(6):738-744. DOI: 10.1007/BF01665308.
9. Wang $P$, Xue $S$, et al. Clinical characteristics and treatment outcomes of parathyroid carcinoma: A retrospective review of 234 cases. Oncol Lett 2017;14(6):7276-7282. DOI: 10.3892/ol.2017.7076.

10. Busaidy NL, Jimenez C, et al. Parathyroid carcinoma: a 22-year experience. Head Neck 2004;26(8):716-726. DOI: 10.1002/hed. 20049.

11. Koea JB, Shaw JH. Parathyroid cancer: biology and management. Surg Oncol 1999;8(3):155-165. DOI: 10.1016/S0960-7404(99)00037-7.

12. Pelizzo MR, Piotto A, et al. Parathyroid carcinoma. Therapeutic strategies derived from 20 years of experience. Minerva Endocrinol 2001;26(1):23-29.

13. Ricci G, Assenza M, et al. Parathyroid carcinoma: the importance of high clinical suspicion for a correct management. Int J Surg Oncol 2012;2012:649148. DOI: 10.1155/2012/649148.

14. Ryhanen EM, Leijon $H$, et al. A nationwide study on parathyroid carcinoma. Acta Oncol 2017;56(7):991-1003. DOI: 10.1080/0284186X.2017.1306103.

15. Wynne AG, van Heerden J, et al. Parathyroid carcinoma: clinical and pathologic features in 43 patients. Medicine (Baltimore) 1992;71(4):197-205. DOI: 10.1097/00005792-199207000-00002.

16. Shane E, Bilezikian JP. Parathyroid carcinoma: a review of 62 patients. Endocr Rev 1982;3(2):218-226. DOI: 10.1210/edrv-3-2-218.

17. Christakis I, Bussaidy N, et al. Differentiating Atypical Parathyroid Neoplasm from Parathyroid Cancer. Ann Surg Oncol 2016;23(9): 2889-2897. DOI: 10.1245/s10434-016-5248-6.

18. Bae JH, Choi HJ, et al. Preoperative predictive factors for parathyroid carcinoma in patients with primary hyperparathyroidism. J Korean Med Sci 2012;27(8):890-895. DOI: 10.3346/jkms.2012.27.8.890.

19. Solorzano CC, Carneiro-Pla DM, et al. Intra-operative parathyroid hormone monitoring in patients with parathyroid cancer. Ann Surg Oncol 2007;14(11):3216-3222. DOI: 10.1245/s10434-007-9590-6.

20. Piciu $D$, Irimie $A$, et al. Highly aggressive pathology of non-functional parathyroid carcinoma. Orphanet J Rare Dis 2013;8:115. DOI: 10.1186/1750-1172-8-115.

21. Suganuma $N$, Iwasaki $H$, et al. Non-functioning parathyroid carcinoma: a case report. Surg Case Rep 2017;3(1):81. DOI: 10.1186/ s40792-017-0357-4.

22. Schantz A, Castleman B. Parathyroid carcinoma. A study of 70 cases. Cancer 1973;31(3):600-605. DOI: 10.1002/1097-0142(197303)31: 3<600::AID-CNCR2820310316>3.0.CO;2-0. 